\title{
Self-reported Sources of Stress, Job Satisfaction and Quality of Care in Professional Hospital Nurses in West-Greece
}

\author{
Eleni Jelastopulu, ${ }^{1, *}$, Thomaella Tsouvaltzidou ${ }^{1}$, Evangelia Vangeli ${ }^{2}$, Fani Messolora ${ }^{2}$, John Detorakis ${ }^{1,2}$, \\ Evangelos C Alexopoulos ${ }^{1,3}$
}

\author{
${ }^{1}$ Public Health Department, Medical School, University of Patras, Patras, Greece \\ ${ }^{2}$ Faculty of Health and Caring Professions, Technological Educational Institute of Patras, Patras, Greece \\ ${ }^{3}$ Onassis Cardiac Surgery Center, Occupational Health Department, Athens, Greece \\ *Corresponding Author: jelasto@upatras.gr
}

Copyright (C) 2013 Horizon Research Publishing All rights reserved.

\begin{abstract}
Occupational stress has been associated with low job satisfaction and poor quality of work performance. The aim of this study was to identify sources of stress among the nursing staff and to evaluate job satisfaction, quality of nursing care and the collaboration between the nursing and medical staff, in order to improve the quality of the provided health care and the working conditions. In this cross sectional study, a questionnaire survey was conducted among 494 randomly selected nurses working in 5 hospitals in the prefecture of Achaia, West-Greece. Statistical analysis was performed using software SPSS v.17.0. The results indicate that stress and work satisfaction are negatively related and that the hospital and the department the participants worked in play a significant role in their work performance. Supervisors' and doctors' support, respect and acceptance influenced the variables under study as well. Additionally, another major factor that emerged from the analysis was the inadequacy of time for care which reveals the lack of personnel and resources. This study underlines the need of creating a supportive and positive working environment for the nursing staff, by reducing sources of stress and introducing intervention programs.
\end{abstract}

Keywords Greece, hospital care, job satisfaction, nurses, occupational stress, quality of care

\section{Introduction}

The hospital sector is considered as high-risk, intensive and demanding industry which affects employees' health $(1,2)$, job satisfaction and quality of life (3). The nursing profession is one of the well-studied professional groups in terms of work-related morbidity $(4,5,6,7)$. Stress arises as a major risk factor in nursing profession with various proven sources like the shift work, excessive workload, violence which may adversely affect personal/family life (5). Exposure to chronic stress results in higher odds for stress-related diseases (cardiovascular disease, hypertension, sleep problems, mental illness) $(8,9,10)$, accidents (2), even fatal injuries (11). Evidence exists on a positive relation between the number of suicides and the levels of stress each nurse experiences (12) and for an increased suicide rate for female nurses (11). Moreover, it results in reduced performance at work (3), increased absence from work, high turnover and financial and human costs (2).

As it has been outlined in previous studies, nursing is by its very nature, an occupation subject to a high degree of stress, confronting every day suffering, grief and death, and with many of its tasks being considered as mundane, unrewarding and degrading (13). Other sources of stress include time-pressures and high responsibilities and the usually "depressive" environment (5), while other factors, such as the nurses' position level, their professional background, including education and job experience $(14,15)$, their co-workers' and superiors' relations $(16,17)$ and the nursing unit they are employed in $(18,19)$ seem to influence the level of psychological distress. However the results are highly variant in different hospital environments within and between countries (20), implying a significant role of district and national level socio-economic and cultural differences. Limited evidence exists on the optimum approach in stress management which further underlines the need for in-depth analysis of stress sources and its interaction with job satisfaction and the various aspects of the quality in nursing care.

The main goals of this study were to explore factors related to self-reported measures of stress, job satisfaction and quality of provided care and the interrelationships in professional hospital nurses in Achaia, Western Greece.

\section{Materials and Methods}




\subsection{Study Population}

The sample comprised 530 nurses working in different clinical wards (including mainly internal medicine, general surgery, orthopedics, intensive care unit, cardiology, pediatrics, and outpatients wards), of five hospitals in the prefecture of Achaia, West-Greece. Selected hospitals included the two tertiary hospitals of Patras, i.e. the University Hospital of Patras (UHP) and the General Hospital St. Andreas (GHStA), including the administrative to the GHStA associated hospitals "409" (H409) and the Pediatric Hospital Karamandaneio (PHK) as well as one smaller hospital in the city of Aigio (HA). Due to administrative conjunction, the H409 was integrated to the GHStA. The overall response rate was $93.2 \%(n=494)$.

\subsection{Data Collection and Instruments}

Data were collected by a self-completed anonymous questionnaire which was distributed and collected in the period from March to July 2008. A review of research literature revealed a number of relevant to our aims self-rating scales. Two were selected, the NDNQI-Adapted Index of Work Satisfaction (21), from which 38 questions (statements) regarding job satisfaction and the quality of the provided nursing care were used and a 38-item job stress inventory for general practitioners designed by Cooper et al. (22) from which 18 questions concerning stress factors were chosen., A final questionnaire was developed consisting of a total of 79 questions divided in four sections, including 14 questions regarding personal and demographic factors and 9 work-contextual items relating to quality of care.

The first section of the questionnaire (14 questions) included mainly individual and job related characteristics such as age, gender, family status, level of education, duration of employment, working hours, level of income, the ward they were presently occupied in and if they hold any expertise and supervising duties.

The second section included questions for nurses to report how stressful 18 sources of stress were on a five-point Likert scale, whereas 1 meant none and 5 extreme. Due to the high correlations among the items of the second section of the questionnaire we applied factor analysis in order to identify the underlying variables (factors) that explain most of the observed variance (for methods of extraction and rotation and scores calculation, see statistical section). Three stress-related factors were extracted from the second part: (i) job demands and content (including questions regarding responsibilities such as "I feel pressure due to the responsibility for patients' lives", "I feel pressure due to the shortage of essential resources", "I feel pressure due to lack of time", the working environment, excessive working hours, bureaucratic work and work overload). Loadings ranged between 0.54 and 0.79 , except one that was 0.46 , Cronbach's alpha was 0.88 ; (ii) family (home) - job conflict (including questions such as "I feel stressed due to the lack of time to cover home demands", "The need to share time between work and family stresses me", "I feel stressed during my night shifts" or "The fear of unjust attacks during visits stresses me"). Loadings ranged between 0.61 and 0.76 , Cronbach's alpha was 0.82; and (iii) patients demands (including questions such as "I feel pressure when having to deal with relatives or difficult patients", "Patients' unreasonable demands stress me", "I am concerned about patients and their complaints"). Loadings ranged between 0.50 and 0.82, Cronbach's alpha was 0.84. Internal consistency reliability for all three factors was found well above Kline 0.70 acceptable limit (23). The total score in each factor was calculated by summation of the corresponding questions.

The third part consisted of 38 questions (statements) regarding the satisfaction the nurses gain from their work on a six-point Likert type scale. The levels of agreement ranged between strongly agree (1) and strongly disagree (6). Due to the high correlations among the items of the third section of the questionnaire, again factor analysis was applied in order to identify the underlying variables (factors) that explain most of the observed variance. In case of a negatively stated question, the scoring was reversed before summations. Six satisfaction-related factors were extracted from the factor analysis of the third section: (i) job satisfaction (including questions such as "I am fairly well satisfied with my job", "My present salary is satisfactory", "I am not considering taking another job", "I have to force myself to go to work much of the time”). Loadings ranged between 0.54 and 0.80 ; (ii) supervisors support (including statements such as "I can count on my superiors to back me up", "Nursing administrators generally consult with the staff on daily problems"). Loadings ranged between 0.55 and 0.56 ; (iii) doctors' support ("Physicians in general collaborate with the nursing staff", "Physicians respect the skill and knowledge of the nursing staff"). Loadings ranged between 0.49 and 0.79 ; (iv) colleagues' support and collaboration (including statements such as "There is a good deal of teamwork among the nursing personnel", "It is hard for new nurses "to feel at home" on the unit"). Loadings ranged between 0.66 and 0.83 ; (v) adequate time for nursing care (including questions such as "I have sufficient time for direct patient care", "I have plenty of time to discuss patient care problems with other nursing service personnel"). Loadings ranged between 0.55 and 0.76 ; and (vi) decision latitude (including statements like "There is ample opportunity for nursing staff to participate in the administrative decision-making process", "I am not satisfied with my participation in decision making for the unit”). Loadings ranged between 0.40 and 0.77 . It was obvious and reasonable that the extracted factors (ii) - (iv) and (v) - (vi) represented conceptually the support and demand/control theoretical framework (model), respectively. Scores were calculated by summing-up the scores of the corresponding questions. Cronbach's alpha exceeded in all cases 0.84 , indicating high internal consistency reliability.

The last section of the questionnaire (9 questions) included nurses' views on various aspects of care and 
focused on the quality of the provided nursing care. For the answers, a four-point scale was used [very good/ good/ fair/ poor)]. Furthermore, they were asked to give a subjective estimation on the improvement of the quality of nursing care during the last years. Finally, they were asked to state (yes/no), if the discharged patients from the hospital are well-prepared for self-care at home.

Table 1. Characteristics of the study population $(n=494)$

\begin{tabular}{|l|c|c|}
\hline & $\mathrm{n}$ & $\%$ \\
\hline Age (in years) & & \\
$<=34$ & 187 & 37.9 \\
$35-44$ & 253 & 51.3 \\
$>44$ & 53 & 10.8 \\
\hline Marital status & & \\
Single & 146 & 29.7 \\
Married & 318 & 64.6 \\
Divorced/Widowed & 29 & 5.7 \\
\hline Number of children & & \\
0 & 173 & 35.3 \\
1 & 65 & 13.3 \\
2 & 184 & 37.6 \\
3 or 4 & 68 & 13.9 \\
\hline Monthly income & & \\
$<1100$ & 303 & 61.3 \\
$1100-1300$ & 149 & 30.2 \\
$>1300$ & 24 & 4.9 \\
\hline Working overtime (>40 hours/week) & & \\
No & 193 & 39.6 \\
Yes & 294 & 60.4 \\
\hline Job title in unit (Department role) & & \\
Simple nurse & 65 & 13.3 \\
Specialized nurse (e.g. surgery, ICU & 340 & 69.7 \\
etc.) & 83 & 17 \\
Head nurse & & \\
\hline Duration of employment & & \\
$<15$ & 243 & 48.6 \\
$15-19$ & 147 & 29.4 \\
$>19$ & 107 & 21.4 \\
\hline Duration of employment in unit & 158 & 31.6 \\
$1-4$ & 342 & 68.4 \\
$>4$ & & \\
\hline & & \\
\hline & & \\
\hline
\end{tabular}

\subsection{Statistical Analysis}

Factor analysis by using principal component analysis with Varimax - Kaiser Normalization as the rotation method was applied to the second and third part of the questionnaire. The commonly used criteria for factor analysis were adopted, i.e. eigenvalue $>1$ and loadings $>0.40$.

To determine if the subscales were suitable for factor analysis Kaiser-Meyer-Olkin (KMO) measure of sampling adequacy and Bartlett's test of sphericity were conducted. Both tests indicated that factor analysis is a good measure for the data for each of the scales.

The internal reliability of the extracted factors was examined by computing Cronbach's alpha correlation coefficient. Cronbach's alpha assesses the degree of inter-item correlation and a value larger than 0.70 is considered satisfactory (23). The total score in each factor was calculated by summation of the corresponding questions while scores in some questions had to be reversed before summations. Following correlation analysis, logistic regression was employed in the dichotomized outcome variables (using the median value as the cut-off point) to assess significant associations included in adjusted multivariate models. Odds ratios (OR) with $95 \%$ confidence intervals $(95 \% \mathrm{CI})$ were calculated as measure of association. Out of 494 valid questionnaires missing values did not exceed $2 \%$ in all variables but income (3.6\%). Statistical analyses were conducted by means of the SPSS v.17 for Windows statistical package.

\section{Results}

Table 1 shows the main individual and job related characteristics of the studied population. The great majority was female $(\mathrm{n}=452,91.3 \%),<45$ years old, married with children and mainly specialized nurses with three or more years of education (Table 1). Out of the total studied population, $40 \%(n=198)$ of the participants worked in the UHP ( $\mathrm{n}=198)$.

Table 2 demonstrates the associations between the job-satisfaction-related factors that originated from the factor analysis and the working hospital and department. Between the hospitals significant differences are observed regarding supervisors' support, adequate time for nursing care and decision latitude. In general, nurses in HA reported the most unfavorable psychosocial environment in terms of support and the lowest job satisfaction while nurses in PHK reported higher adequate time for nursing care and better decision latitude. Concerning stress, PHK nurses reported less stress due to job demands and content (but not significant in non-parametric testing), while HA nurses reported higher levels of stress due to family-work conflict. Between departments, unfavorable conditions and more stress were reported by nurses in surgery and orthopedics wards (Table 2). Other individual and job-related variables scarcely exhibited significant interrelations such as age with job satisfaction (Kruskal-Wallis, $\mathrm{p}=0.021$ ) and decision latitude (Kruskal-Wallis, $\mathrm{p}=0.003$ ); monthly income with colleagues' support (Kruskal-Wallis, $\mathrm{p}=0.031$ ); and number of children with family (home)-job conflict (Kruskal-Wallis, $\mathrm{p}=0.020$ ). 
Table 2. Total scores in the main variables under study and its distribution across the hospitals and departments $[\mathrm{JS}=\mathrm{J}$ ob satisfaction, $\mathrm{SS}=\mathrm{Supervisors}$ ' support, DS=Doctors' support, $\mathrm{CS}=$ Colleagues' support, $\mathrm{AT}=$ Adequate time for nursing care, DL=Decision latitude, NS=Non significant, UHP=University Hospital of Patras, GHStA=General Hospital St.Andreas, H409=Hospital 409, HA=Hospital of Aigio, PHK=Pediatric Hospital Karamandaneio]

\begin{tabular}{|c|c|c|c|c|c|c|c|c|}
\hline & $\mathrm{N}$ & $\%$ & $\begin{array}{c}\text { SS } \\
\text { Mean } \\
(\mathrm{SD})\end{array}$ & $\begin{array}{c}\text { JS } \\
\text { Mean } \\
(\mathrm{SD})\end{array}$ & $\begin{array}{c}\text { DS } \\
\text { Mean } \\
(\mathrm{SD})\end{array}$ & $\begin{array}{l}\text { NS } \\
\text { Mean } \\
(\mathrm{SD})\end{array}$ & $\begin{array}{c}\text { AT } \\
\text { Mean } \\
(\mathrm{SD})\end{array}$ & $\begin{array}{c}\text { DL } \\
\text { Mean } \\
(\mathrm{SD})\end{array}$ \\
\hline All & 494 & 100 & $\begin{array}{l}6.14 \\
(2.7)\end{array}$ & $\begin{array}{c}32.84 \\
(6.8)\end{array}$ & $\begin{array}{c}22.07 \\
(6.7)\end{array}$ & $\begin{array}{c}17.43 \\
(4.6)\end{array}$ & $\begin{array}{c}26.51 \\
(5.6)\end{array}$ & $\begin{array}{c}24.82 \\
(5.5)\end{array}$ \\
\hline $\begin{array}{c}\text { HOSPITAL } \\
\text { UHP }\end{array}$ & 198 & 40.1 & $\begin{array}{c}\mathrm{P}<0.001 \mathrm{a} \\
5.37 \\
(2.6)\end{array}$ & $\begin{array}{c}\mathrm{P}=0.001 \mathrm{a} \\
32,76 \\
(6,7)\end{array}$ & $\begin{array}{l}\mathrm{NS} \mathrm{a} \\
22.72 \\
(6.2)\end{array}$ & $\begin{array}{l}\mathrm{NS} \mathrm{a} \\
16.98 \\
(4.3)\end{array}$ & $\begin{array}{c}\mathrm{P}<0.001 \mathrm{a} \\
27.32 \\
(5.1)\end{array}$ & $\begin{array}{c}\mathrm{P}<0.001 \mathrm{a} \\
25.70 \\
(5.2)\end{array}$ \\
\hline GHStA/H409 & 203 & 41.1 & $\begin{array}{l}6.70 \\
(2.6)\end{array}$ & $\begin{array}{c}32.68 \\
(6.8)\end{array}$ & $\begin{array}{c}22.08 \\
(6.8)\end{array}$ & $\begin{array}{l}17.70 \\
(4.5)\end{array}$ & $\begin{array}{c}26.13 \\
(5.7)\end{array}$ & $\begin{array}{c}24.22 \\
(5.5)\end{array}$ \\
\hline HA & 50 & 10.1 & $\begin{array}{l}6.84 \\
(3.0)\end{array}$ & $\begin{array}{c}36.18 \mathrm{a} \\
(7.1)\end{array}$ & $\begin{array}{c}22.08 \\
(9.0)\end{array}$ & $\begin{array}{l}19.29 \\
(5.3)\end{array}$ & $\begin{array}{r}27.57 \\
(6.0)\end{array}$ & $\begin{array}{c}26.42 \\
(5.9)\end{array}$ \\
\hline PHK & 43 & 8.7 & $\begin{array}{l}6.19 \\
(2.3) \\
\end{array}$ & $\begin{array}{c}30.05 \\
(5.3) \\
\end{array}$ & $\begin{array}{c}19.00 \\
(5.0)\end{array}$ & $\begin{array}{c}16.16 \\
(4.3)\end{array}$ & $\begin{array}{c}23.30 \mathrm{a} \\
(5.0)\end{array}$ & $\begin{array}{c}21.74 a \\
(4.4)\end{array}$ \\
\hline $\begin{array}{l}\text { WARDS } \\
\text { Surgery and } \\
\text { Orthopedics } \\
\text { Any other }\end{array}$ & 372 & 76.1 & $\begin{array}{l}\text { NS } \\
5.89 \\
(2.9) \\
6.19 \\
(2.6)\end{array}$ & $\begin{array}{c}\mathrm{P}=0.045 \\
33.88 \\
(7.1) \\
32.44 \\
(6.6)\end{array}$ & $\begin{array}{c}\mathrm{P}<0.001 \\
26.13 \\
(6.5) \\
20.78 \\
(6.3)\end{array}$ & $\begin{array}{l}\mathrm{NS} \\
17.44 \\
(4.7) \\
17.37 \\
(4.4)\end{array}$ & $\begin{array}{c}\mathrm{P}<0.001 \mathrm{a} \\
28.10 \\
(5.5) \\
26.01 \\
(5.5)\end{array}$ & $\begin{array}{c}\mathrm{P}=0.004 \mathrm{a} \\
26.56 \\
(5.5) \\
24.25 \\
(5.3)\end{array}$ \\
\hline
\end{tabular}

${ }^{a}$ non parametric testing including Kruskal-Wallis or Mann-Whitney test;

Most psychosocial variables were moderate to highly interrelated. The strength of the association is given in Table 3. All correlations were significant at the 0.01 level (2-tailed).

Table 3. Significant correlations (Spearman's rho) among the support and control-demand statements of nursing staff [JS=Job satisfaction, $\mathrm{SS}=$ Supervisors' support, DS=Doctors' support, $\mathrm{CS}=$ Colleagues' support, $\mathrm{AT}=$ Adequate time for nursing care, $\mathrm{DL}=$ Decision latitude $]$

\begin{tabular}{|c|c|c|c|c|c|}
\hline $\begin{array}{c}\text { Variables } \\
\text { (valid cases, } \mathrm{n} \text { ) }\end{array}$ & SS & DS & CS & AT & DL \\
\hline JS (493) & 0.361 & 0.333 & 0.258 & 0.476 & 0.517 \\
\hline SS (493) & & 0.267 & 0.318 & 0.198 & 0.344 \\
\hline DS (493) & & & 0.315 & 0.337 & 0.449 \\
\hline CS (493) & & & & 0.137 & 0.229 \\
\hline AT (492) & & & & & 0.508 \\
\hline
\end{tabular}

\subsection{Stress Factors}

Table 4 shows the multivariate analysis of stress factors. Nurses over 44 years of age and head nurses, have two times higher pressure due to the demands of the job. The conflict between home and job demands concerned mostly nurses with three or more children, low incomes, specialized nurses working in the surgery and orthopedics department and nurses who complained about low support by their supervisors. The support and respect given, both by supervisors and doctors, seem to be important for copying with stress originating from the demands of their job. All stress factors were influenced by the inadequacy of time by the staff to handle their nursing tasks. Likewise, nurses occupied in the surgical and orthopedics wards felt pressure due to all three, job, home and patients demands. Paradoxically, working overtime seemed to lead to less stress due to family-job conflict (Table 4). 
Table 4. Multivariate analysis of stress sources (higher than average levels) in nurses ( $\mathrm{n}=494)$ a $[\mathrm{NS}=\mathrm{Non}$ significant, UHP=University Hospital of Patras, GHStA=General Hospital St.Andreas, H409=Hospital 409, HA=Hospital of Aigio, PHK=Pediatric Hospital Karamandaneio, OR=odds ratio, $95 \% \mathrm{CI}=95 \%$ confidence interval]

\begin{tabular}{|c|c|c|c|c|c|c|}
\hline & & & \multicolumn{2}{|c|}{ Stress due to } & & \\
\hline & \multicolumn{2}{|c|}{ job demands and content } & \multicolumn{2}{|c|}{ family (home) - job conflict } & \multicolumn{2}{|c|}{ patients demands } \\
\hline & OR & $95 \% \mathrm{CI}$ & OR & $95 \% \mathrm{CI}$ & OR & $95 \% \mathrm{CI}$ \\
\hline $\begin{array}{c}\text { Age (in years) } \\
<=34 \\
35-44 \\
>44\end{array}$ & $\begin{array}{c}1 \\
1.04 \\
2.09\end{array}$ & $\begin{array}{l}0.64-1.70 \\
0.88-4.97\end{array}$ & NS & & NS & \\
\hline $\begin{array}{c}\text { Number of children } \\
0 \\
1 \\
2 \\
3 \text { or more } \\
\end{array}$ & NS & & $\begin{array}{c}1 \\
1.66 \\
1.34 \\
4.05 \\
\end{array}$ & $\begin{array}{l}0.84-3.28 \\
0.79-2.27 \\
\mathbf{2 . 0 2 - 8 . 1 4} \\
\end{array}$ & NS & \\
\hline $\begin{array}{c}\text { Monthly income (Euros) } \\
<1100 \\
1100-1300 \\
>1300 \\
\end{array}$ & $\begin{array}{c}1 \\
1.30 \\
0.40 \\
\end{array}$ & $\begin{array}{l}0.78-2.16 \\
0.13-1.23\end{array}$ & $\begin{array}{c}1 \\
0.78 \\
0.28\end{array}$ & $\begin{array}{c}0.47-1.31 \\
0.09-0.84\end{array}$ & NS & \\
\hline $\begin{array}{c}\text { Working overtime } \\
\text { No } \\
\text { Yes } \\
\end{array}$ & NS & & $\begin{array}{c}1 \\
0.60\end{array}$ & $0.38-0.96$ & NS & \\
\hline $\begin{array}{c}\text { Department role } \\
\text { Simple nurse } \\
\text { Specialized nurse (e.g. } \\
\text { clinical surgery etc.) } \\
\text { Head nurse }\end{array}$ & $\begin{array}{c}1 \\
1.65 \\
2.04\end{array}$ & $\begin{array}{l}0.82-3.33 \\
0.88-4.73\end{array}$ & $\begin{array}{c}1 \\
2.25 \\
1.62\end{array}$ & $\begin{array}{l}1.11-4.55 \\
0.70-3.75\end{array}$ & NS & \\
\hline $\begin{array}{c}\text { Hospital } \\
\text { PHK } \\
\text { UHP } \\
\text { GHStA and H409 } \\
\text { HA }\end{array}$ & NS & & $\begin{array}{c}1 \\
0.67 \\
0.43 \\
1.25\end{array}$ & $\begin{array}{l}0.30-1.50 \\
0.19-0.96 \\
0.45-3.49 \\
\end{array}$ & $\begin{array}{c}1 \\
0.78 \\
0.56 \\
0.32 \\
\end{array}$ & $\begin{array}{l}0.38-1.62 \\
0.27-1.16 \\
0.12-0.80\end{array}$ \\
\hline $\begin{array}{c}\text { Department (wards) } \\
\text { Surgery and } \\
\text { Orthopedics } \\
\text { Any other }\end{array}$ & $\begin{array}{c}2.24 \\
1 \\
\end{array}$ & $1.30-3.84$ & $\begin{array}{c}2.15 \\
1 \\
\end{array}$ & $1.30-3.57$ & $\begin{array}{c}1.45 \\
1 \\
\end{array}$ & $0.91-2.33$ \\
\hline Low supervisor support & 1.65 & $1.05-2.59$ & 1.86 & $1.18-2.93$ & NS & \\
\hline Low doctors support & 1.81 & $1.15-2.85$ & NS & & 1.93 & $1.29-2.87$ \\
\hline Inadequate time for care & 4.28 & $2.75-6.68$ & 1.68 & $1.08-2.62$ & 1.53 & $1.03-2.26$ \\
\hline Nagelkerke R Square & 0.27 & & 0.22 & & 0.20 & \\
\hline
\end{tabular}

Covariates of the final model $(\mathrm{p}<0.05)$ in bold and italics; all the other variables are adjusted for the final model (were significant in univariate analysis)

Table 5. Multivariate analysis of job satisfaction (lower than average) in professional hospital nurses ( $\mathrm{n}=494$ ) [UHP=University Hospital of Patras, GHStA $=$ General Hospital St.Andreas, $\mathrm{H} 409=$ Hospital 409, HA=Hospital of Aigio, $\mathrm{PHK}=$ Pediatric Hospital Karamandaneio, OR=odds ratio, $95 \% \mathrm{CI}=95 \%$ confidence interval]

\begin{tabular}{|c|c|c|c|}
\hline & OR & \multicolumn{2}{|c|}{$95 \% \mathrm{CI}$} \\
\hline \multirow{2}{*}{\multicolumn{4}{|c|}{$\begin{array}{c}\text { Age (in years) } \\
<=34\end{array}$}} \\
\hline & & & \\
\hline $35-44$ & 1,05 & 0,67 & 1,65 \\
\hline$>44$ & 0,49 & 0,23 & 1,03 \\
\hline \multicolumn{4}{|l|}{ Hospital a } \\
\hline PHK & 1 & & \\
\hline UHP & 0,94 & 0,42 & 2,10 \\
\hline GHStA \& H409 & 1,15 & 0,53 & 2,51 \\
\hline HA & 4,65 & 1,59 & 13,61 \\
\hline Low doctors support & 1,39 & 0,91 & 2,13 \\
\hline Low colleagues' support & 1,46 & 0,96 & 2,23 \\
\hline Inadequate time for care ${ }^{a}$ & 2,57 & 1,67 & 3,96 \\
\hline Low decision latitude $^{a}$ & 3,84 & 2,51 & 5,89 \\
\hline Nagelkerke R Square & 0,34 & & \\
\hline
\end{tabular}

${ }^{a}$ covariates of the final model $(\mathrm{p}<0.05)$; all other variables are adjusted for the final model (which were significant in univariate analysis) 


\subsection{Job Satisfaction Factors}

Table 5 presents the results of the multivariate analysis regarding the factors that influence job satisfaction. Nurses in the smaller HA report 4.7 lower job satisfaction compared to the nurses working in the other hospitals. Important factors for low satisfaction were the limited support both from supervisors and colleagues, the inadequate time for care and the lack of participation in decision making.

\subsection{Quality of Nursing Care}

Concerning the main aspects of quality of care, $58 \%$ of nurses described the care as good or excellent and $51 \%$ stated the quality of care having improved during the last years. Having not enough time to report nursing care stated $41 \%$, and $27 \%$ admitted to neglect important tasks regarding their patients. Head nurses were two times more dissatisfied with the quality of care provided in their unit then simple nurses, while nurses working in surgical and orthopedics departments admitted neglecting important nursing tasks more often, compared to nurses of other wards. Nurses complaining about low doctors' and co-workers' support mentioned lower quality of care in their unit, reported insufficient time to report nursing care and admitted to neglect more often important tasks. Nurses who complained about limited decision latitude have not enough time to report nursing care (Table 6).

\section{Discussion}

This cross-sectional study was undertaken to explore in a comprehensive way the factors related to stress, job satisfaction and quality of provided care in professional hospital nurses in Achaia, Western Greece. The findings demonstrate that the well-known factors of the demand-control-support model of occupational stress are highly inter-related and influence both job satisfaction and the quality of provided care.

As described in other studies $(15,24)$, the highest work-related pressure was experienced by nurses with expertise and in high positions, such as head nurses or supervisors, or nurses with higher education. Their responsibilities expand over a variety of fields, such as the training and the supervision of the simple nurses or the nurses undergoing practice, the caring for the recovery or even the lives of their patients and the management of economical matters, vital for the procurement of drugs and other medical supplies and for the smooth functioning of their ward in general, increasing thus the levels of stress and anxiety (25).

However, it seems that generally nurses older than 44 years of age perceived their work as stressful, since their physical fatigue keeps reducing their strength to cope with the demands of their everyday duties $(15,26)$. Another factor that oppresses and influences nurses' work performance is a low monthly income, as described in other studies $(27,28,29)$.

This study also revealed that both the level of nursing care the nurses offer and the level of stress they experience are associated with their private lives. Nurses without children are more likely to enjoy their work, providing higher support and more time to their patients, raising thus the level of quality of hospital care, whereas nurses with three and more children may find their job demands coming in conflict with their family responsibilities $(15,26,30,31)$.

Table 6. Multivariate analysis on quality of care $(\mathrm{QC})$ aspects in professional hospital nurses $(\mathrm{n}=494)$ a $[\mathrm{NS}=\mathrm{Non}$ significant, $\mathrm{OR}=\mathrm{Odds}$ ratio, $95 \% \mathrm{CI}=95 \%$ confidence interval]

\begin{tabular}{|c|c|c|c|}
\hline & Less than good QC in unit & Not enough time to report & Neglect important tasks \\
\hline & OR $(95 \% \mathrm{CI})$ & OR $(95 \% \mathrm{CI})$ & OR $(95 \% \mathrm{CI})$ \\
\hline $\begin{array}{c}\text { Job title in unit (role) } \\
\text { Simple nurse } \\
\text { Specialized } \\
\text { Head nurse } \\
\end{array}$ & $\begin{array}{c}1 \\
1.13(0.62-2.06) \\
2.14(1.04-4.39) \\
\end{array}$ & NS & NS \\
\hline $\begin{array}{c}\text { Department (ward) } \\
\text { Surgery and Orthopedics } \\
\text { Any other }\end{array}$ & NS & NS & $\begin{array}{c}1.87(1.18-2.97) \\
1\end{array}$ \\
\hline Low supervisors' support & $N S$ & $N S$ & $1.55(1.01-2.37)$ \\
\hline Low doctors' support & $1.45(0.97-2018)$ & $1.79(1.18-2.72)$ & $1.14(0.73-1.78)$ \\
\hline Low colleagues' support & $1.76(1.18-2.61)$ & $1.33(0.88-2.01)$ & $1.75(1.14-2.68)$ \\
\hline Inadequate time for care & $N S$ & $1.29(0.82-2.01)$ & $1.27(0.83-1.96)$ \\
\hline Low decision latitude & $N S$ & $2.24(1.48-3.39)$ & $1.17(0.76-1.81)$ \\
\hline Low job satisfaction & $N S$ & $1.44(0.93-2.24)$ & NS \\
\hline Stress due to job demands & $1.52(1.02-2.26)$ & $1.94(1.29-2.94)$ & NS \\
\hline Nagelkerke R Square & 0.10 & 0.16 & 0.11 \\
\hline
\end{tabular}

Covariates of the final model $(\mathrm{p}<0.05)$ in bold and italics; all the other variables are adjusted for the final model (were significant in univariate analysis) 
There are no previous studies to investigate the differences between hospitals in Greece, another factor that proved to be important in the accumulation of work pressure in nurses in the present study, revealing conflicting data. The UHP, being the largest in equipment and personnel tertiary care hospital in Western Greece, is called to treat emergencies and critically ill patients referred to from neighboring rural primary care facilities, such as the HA, lacking in specialized staff and essential equipment $(32,33)$. However, UHP nurses appear to gain more pleasure from their work then their colleagues in HA. This positive view could be explained by the division of duties in the well-staffed UHP and the satisfaction of being able to offer total health care to their patients.

Concerning the specialized pediatric hospital PHK in the region of Western Greece, the study reveals higher levels of stress due to patients and work demands in comparison to the bigger hospitals of Patras that could be explained with an increased sensitivity and compassion when handling with children and a higher psychological burden, especially when dealing with dying children $(14,34,35)$. As other studies have shown, nurses working in a pediatric hospital never feel that the time and care they offer to their young patients are enough $(36,37)$.

The observed differences in the perception of stress and the provided nursing care between the various wards are in agreement with other studies that examined healthcare personnel occupied in surgical and orthopedics departments $(38,39)$, where the participants reported disappointing levels of work satisfaction and quality of care, as well as high levels of stress due to both job and patients' demands. The responsibility towards critically ill and dying patients and the psychological wear by their relatives' pain and grief are clearly greater than in other less demanding clinics.

In the present study, further stress increasing and satisfaction reducing factors are the limited decision latitude and autonomy (40), low participation in decision making (41) and low supervisors' support $(16,42)$. As other studies have shown, lack of support and respect and lack of communication and collaboration between doctors and colleagues affect negatively the quality of the provided nursing care $(43,44)$.

However, in contrast to other studies $(45,46)$, the present study revealed higher stress levels in nurses with regular working hours. This paradox could be explained by the lower salary they receive and the difficulties to cover their everyday family expenses.

Several studies have demonstrated that nurses as an occupational group are subjected to high levels of stress and burnout $(5,6)$, but no controlled intervention studies are reported in the literature to try and reduce stress levels.

An important limitation of the present study is that the data were collected 5 years ago and prior to the financial crisis in Greece and the severe shortages in salaries but also in other resources as basic supplies and equipment. However, this study is valuable for future comparisons especially in terms of measuring the impact of the financial crisis on stress and job satisfaction among nurses. Future research should investigate mainly in coping strategies, how to decrease stress, burnout and turnover in nursing.

It should be a priority for the Greek Ministry of Health to invest in its social healthcare system by employing more nursing staff and raising nurses' incomes, in order for nurses to find the time and fortitude to develop a closer and more emotional involvement with their patients $(47,48,49$, 50). Another important matter that the Ministry must add in its agenda is the enhancement of smaller hospital units with the provision of medical material and equipment and the reinforcement of the workforce with doctors of more medical specialties, in order to reduce the burden of larger hospitals. Working women with children should also be taken into consideration, by reducing their working hours and permitting to them longer maternal leaves. Furthermore, it is wishful for nurses to be transferred periodically to different wards, in order to avoid falling into a routine schedule and to enhance the enthusiasm for their work, even after many working years.

Providing them a higher level of pre- and postgraduate education and continuing education courses will lead to increased confidence and an ability to discuss issues as equals with professional colleagues $(51,52)$. Better relationships with other healthcare professions may also relieve stress and pressure and promote the successful functioning of the clinic $(44,53)$. This can be achieved through closer association during their training, in order to enhance the understanding of each others' roles and contribution. Finally, it is important for managers to be concerned about providing a positive and supportive environment in which nurses can share, communicate and support each other in terms of their feelings and problems $(54,55)$ and introducing relaxation techniques and stress management workshops (56). Hospital managers or supervisors should involve nurses in periodical meeting with them about the development goals of their units and provide ways to enhance their influence in the making of important changes within the hospital and introduce holistic care as part of the nursing ethos $(42,57,58,59)$. It is essential to care for the nursing staff, by developing specific "anti-stress" measures, in order to enhance their job satisfaction and improve the quality of the provided nursing care.

\section{Acknowledgements}

We would like to thank all the nurses participating in the survey and the hospital managers for supporting this study.

\section{REFERENCES}

[1] WHO (World Health Organization) [Internet]. Occupational 
health (Health workers). c2012. Available from http:/www.who.int/occupational_health/topics/hcworkers/en /

[2] ILO (International Labour Organization) [Internet]. Occupational Injuries [Main statistics (annual): Cases of injuries with lost workdays, rates of occupational injuries, days lost by economic activity]. c2008. Available from http://laborsta.ilo.org

[3] Visser MRM, Smets EMA, Oort FJ, De Haes HCJM. Stress, satisfaction and burnout among Dutch medical specialists. Can Med Assoc J. 2003;168:271-5

[4] Alexopoulos EC, Burdorf A, Kalokerinou A. Risk factors for musculoskeletal disorders among nursing personnel in Greek hospitals. Int Arch Occup Environ Health. 2003;76:289-94

[5] McVicar. A Workplace stress in nursing: A literature review. J Adv Nurs. 2003;44: 633-42

[6] Butterworth T, Carson J, Jeacock J, White E, Clements A. Stress, coping, burnout and job satisfaction in British nurses: Findings from the clinical supervision evaluation project. Stress Medicine. 1999;15:27-33

[7] Alexopoulos EC, Tanagra D, Detorakis I, Gatsi P, Goroyia A, Michalopoulou M, et al. Knee and low back pain in professional hospital nurses: Occurrence, Chronicity, care seeking and absenteeism. Work. 2011;38:329-35

[8] Faragher EB, Cass M., Cooper CL. The relationship between job satisfaction and health: A meta-analysis. Occup Environ Med. 2005;62:105-12

[9] Rozanski A, Blumenthal JA, Kaplan J. Impact of psychological factors on the pathogenesis of cardiovascular disease and implications for therapy. Circulation. 1999;99:2192-217

[10] Weinberg A, Creed F. Stress and psychiatric disorder in healthcare professionals and hospital staff. Lancet. $2000 ; 355: 533-7$

[11] Bureau of Labor Statistics [Internet]. National Census of Fatal Occupational Injuries in 2006. c2007. Available from http://www.bls.gov/news.release/archives/cfoi_08092007.pd f

[12] Feskanich D, Hastrup JL, Marshall JR, Colditz GA, Stampfer MJ, Willett WC, et al. Stress and suicide in the nurses' health study. J Epidemiol Commun H. 2002;56:95-8

[13] McGrath A, Reid N, Boore. Occupational stress in nursing. International Journal of nursing studies (1989), 26, 359-368. Int J Nurs Stud. 2003;40:555-65; discussion 567-9

[14] Callaghan P, Tak-Ying SA, Wyatt PA. Factors related to stress and coping among Chinese nurses in Hong Kong. J Adv Nurs. 2000;31:1518-27

[15] Lin F, St John W, McVeigh C. Burnout among hospital nurses in China. J Nurs Manag. 2009;17:294-301

[16] Hall DS. The relationship between supervisor support and registered nurse outcomes in nursing care units. Nurs Adm Q. 2007;31:68-80

[17] Severinsson EI, Kamaker D. Clinical nursing supervision in the workplace - Effects on moral stress and job satisfaction. $\mathbf{J}$ Nurs Manag. 1999;7:81-90
[18] Price M. Job satisfaction of registered nurses working in an acute hospital. Br J Nurs. 2002;11:275-80

[19] Dewe PJ. Investigating the frequency of nursing stressors: a comparison across wards. Soc Sci Med. 1988;26:375-80

[20] Aiken LH, Clarke SP, Sloane DM, Sochalski JA, Busse R, Clarke H, et al. Nurses' reports on hospital care in five countries. Health Aff. 2001;20:43-53

[21] Taunton RL, Bott MJ, Koehn ML, Miller P, Rindner E, Pace $\mathrm{K}$, et al. The NDNQI-Adapted Index of work satisfaction. J Nurs Meas. 2004;12(2): 101-22

[22] Cooper GL, Rout U, Faragher B. Mental health, job satisfaction, and job stress among general practitioners. $\mathrm{Br}$ Med J. 1989;298:366-70

[23] Kline PA. A psychometrics primer London. Free Association Books, London, UK; 2000

[24] Admi H, Moshe-Eilon Y. Stress among charge nurses: tool development and stress measurement. Nurs Econ. 2010;28:151-8

[25] Goldblatt H, Granot M, Admi H, Drach-Zahavy A. The experience of being a shift-leader in a hospital ward. J Adv Nurs. 2008;63:45-53

[26] Milutinović D, Grujić N, Jocić N. Identification and analysis of stress factors at nursing workplace: a comparative study of four clinical departments. Med Pregl. 2009;62:68-73

[27] Gardulf A, Söderström IL, Orton ML, Eriksson LE, Arnetz B, Nordström, G. J Nurs Manag. 2005;13:329-37

[28] Klopper HC, Coetzee SK, Pretorius R, Bester P. Practice environment, job satisfaction and burnout of critical care nurses in South Africa. J Nurs Manag. 2012;20:685-95

[29] Malone J. Greek nurses reach crisis point. Nurs Stand. 2012;26:18-19

[30] Capodaglio EM, Di Liddo E. Subjective aspects of quality of life in hospital workers [Aspetti soggettivi della qualità di vita in operatori ospedalieri]. G Ital Med Lav Ergon. 2007;29(1 Suppl A):A24-9

[31] Demirci S, Yildirim YK, Ozsaran Z, Uslu R, Yalman D, Aras AB. Evaluation of burnout syndrome in oncology employees. Med Oncol. 2010;27:968-74

[32] Oikonomidou E, Anastasiou F, Dervas D, Patri F, Karaklidis D, Moustakas P, et al. Rural primary care in Greece: Working under limited resources. Int J Qual Health C. 2010;22:333-7

[33] Oikonomou N, Tountas Y. Insufficient primary care services to the rural population of Greece. Rural Remote Health. $2011 ; 11: 1661$

[34] McCarthy VJ, Power S, Greiner BA. Perceived occupational stress in nurses working in Ireland. Occup Med. 2010;60:604-10

[35] Subih M, Alamer R, Al Hadid L, Alsatari M. Stressors amongst Jordanian nurses working in different types of hospitals and the effect of selected demographic factors: A descriptive- explorative study. Jordan Med J. 2011;45:331-40

[36] Papadatou D, Bellali T, Papazoglou I, Petraki D. Greek nurse and physician grief as a result of caring for children dying of cancer. Pediatr Nurs. 2002;28:345-53 
[37] McCloskey S, Taggart L. How much compassion have I left? An exploration of occupational stress among children's palliative care nurses. Int J Palliat Nurs. 2010;16:233-240

[38] Sharma A, Sharp DM, Walker LG, Monson JRT. Stress and burnout among colorectal surgeons and colorectal nurse specialists working in the National Health Service. Colorectal Dis. 2008;10:397-406

[39] Sili A, Vellone E, Fida R, Alvaro R, Avallone F. Operating theatre and ward nurses: Two different ways of perceiving one's organizational health [Infermieri di camera operatoria e infermieri di medicina generale: La diversa percezione della propriasalute organizzativa] Med Lav. 2010;101:458-470

[40] Blegen MA. Nurses' job satisfaction: a meta-analysis of related variables. Nurs Res. 1993;42: 36-41

[41] Demerouti E, Bakker AB, Nachreiner F, Schaufeli WB. A model of burnout and life satisfaction amongst nurses. J Adv Nurs. 2000;32:454-464

[42] McGilton KS, McGillis Hall L, Boscart V, Brown M. Effects of director of care support on job stress and job satisfaction among long-term care nurse supervisors. Nurs Leadersh (Tor Ont). 2007;20:52-66

[43] Jenkins R, Elliott P. Stressors, burnout and social support: nurses in acute mental health settings. J Adv Nurs. 2004;48:622-631

[44] Kydona CK, Malamis G, Giasnetsova T, Tsiora V, Gritsi-Gerogianni N. The level of teamwork as an index of quality in ICU performance. Hippokratia. 2010;14:94-97

[45] Crespy J, Saurer A. A study on occupational stress of nurses [ETUDE HORAIRE-SANTE CHEZ LES INFIRMIERES]. Soz Praventiv Med. 1981;26:184-7

[46] Patrick K, Lavery JF. Burnout in nursing. Aust J Adv Nurs. 2007;24:43-8

[47] Needleman J, Buerhaus P, Mattke S, Stewart M, Zelevinsky K. Nurse-staffing levels and the quality of care in hospitals. New Engl J Med. 2002;346:1715-1722

[48] Garretson S. Nurse to patient ratios in American health care. Nurs Stand. 2004;19:33-7
[49] Abbott PD, Schepp KG, Zierler BK, Ward D. The use of nurse practitioners and physician assistants in Washington and Oregon emergency departments: A descriptive study of current practice. Adv Emerg Nurs J. 2010;32:338-45

[50] Rickard G, Lenthall S, Dollard M, Oppie T, Knight S, Dunn S, et al. Organizational intervention to reduce occupational stress and turnover in hospital nurses in the Northern Territory, Australia. Collegian 2012,19(4):211-21

[51] Goodman MJ, Schorling JB. A mindfulness course decreases burnout and improves well-being among healthcare providers. Int J Psychiatry Med. 2012;43:119-28

[52] Zadeh S, Gamba N, Hudson C, Wiener N. Taking care of care providers: a wellness program for pediatric nurses. J Pediatr Oncol Nurs. 2012;21:2247-61

[53] Hayhurst A, Saylor C, Stuenkel D. Work environmental factors and retention of nurses. J Nurs Care Qual. 2005;20:283-88

[54] Laschinger HKS, Wong C, McMahon L, Kaufmann C. Leader behavior impact on staff nurse empowerment, job tension, and work effectiveness. J Nurs Adm. 1999;29:28-39

[55] Kenny A, Allenby A. Implementing clinical supervision for Australian rural nurses. Nurse Educ Pract. Nurse Educ Pract. 2013 May;13(3):165-9

[56] Edwards D, Burnard P. A systematic review of stress and stress management interventions for mental health nurses. $\mathrm{J}$ Adv Nurs. 2003;42:169-200

[57] Li IC, Chen YC, Kuo HT. The relationship between work empowerment and work stress perceived by nurses at long-term care facilities in Taipei city. J Clin Nurs. 2008; $17: 3050-8$

[58] Ning S, Zhong H, Libo W, Qiujie L. The impact of nurse empowerment on job satisfaction. J Adv Nurs. 2009;65:2642-8

[59] Wåhlin I, Ek AC, Idvall E. Staff empowerment in intensive care: nurses' and physicians' lived experiences. Intensive Crit Care Nurs. 2010;26:262-9 